
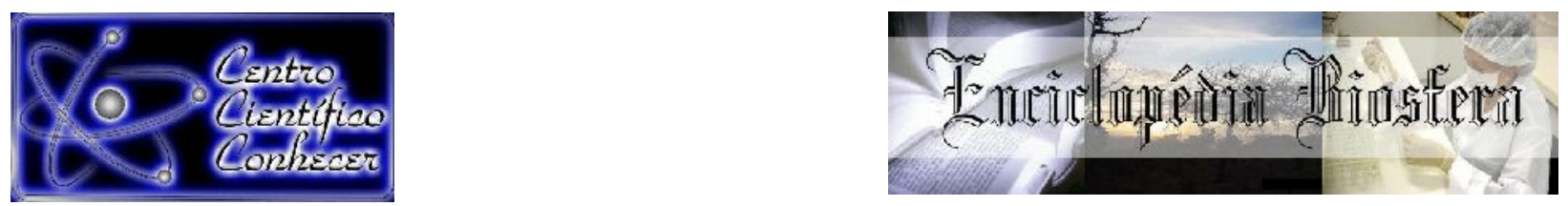

\title{
QUIMIOTERÁPICOS ANTINEOPLÁSICOS DERIVADOS DE PLANTAS
}

Vanessa de Souza Vieira ${ }^{1}$, Vanessa de Sousa $\mathrm{Cruz}^{2}$, Nayane Peixoto Soares ${ }^{1}$, Jaciele Oliveira da Silva ${ }^{3}$, Eugênio Gonçalves Araújo ${ }^{4}$

${ }^{1}$ Doutoranda do Programa de Pós-Graduação em Ciência Animal da Escola de Veterinária e Zootecnia da Universidade Federal de Goiás - Campus Samambaia

E-mail: biovanessa23@hotmail.com

${ }^{2}$ Pós doutoranda, Laboratório Multiusuário de Cultivo Celular da Universidade Federal de Goiás - Campus Samambaia

${ }^{3}$ Mestranda em Produção Vegetal na Universidade Federal de Goiás - Regional Jataí

${ }^{4}$ Professor Doutor do Setor de Patologia Veterinária da Universidade Federal Goiás - Campus Samambaia

Recebido em: 15/11/2020 - Aprovado em: 15/12/2020 - Publicado em: 30/12/2020 DOI: 10.18677/EnciBio_2020D34

\section{RESUMO}

Os principais tratamentos contra o câncer são a quimioterapia, a radioterapia, cirurgia, terapia hormonal e imunoterapia. A quimioterapia é a técnica mais utilizada, e consiste na destruição das células cancerígenas, que se caracteriza por apresentar uma divisão mais rápida que a divisão de uma célula normal. Porém, ainda é uma técnica que causa efeitos adversos em células normais devido à sua alta toxicidade. É consenso entre pesquisadores e profissionais de saúde, que é necessário empregar medicamentos que apresentem maior eficiência e menor efeito adverso para o tratamento do câncer. Neste sentido, diversos centros de excelência em pesquisa têm buscado o desenvolvimento de novos quimioterápicos a partir de plantas, atualmente $60 \%$ das drogas utilizadas em ensaios clínicos são derivados de produtos naturais. Diante do exposto, esta revisão de literatura teve como objetivo apresentar os quimioterápicos antineoplásicos derivados de algumas espécies vegetais, os quais têm sido utilizados no tratamento do câncer. São eles, paclitacel e docetaxel, vimblastina, vincristina, vindesina e vinorelbina, camptotecina, topotecano e irinotecano, podofilotoxina, etoposídeo e teniposídeo, extraídos de plantas da espécie Catharanthus roseus, Camptotheca accuminata, Taxus brevifolia, Podophyllum peltatum. Estes compostos de fontes naturais são hoje empregados com frequência na quimioterapia, todavia outros compostos com propriedades promissoras na utilização antineoplásica estão em fase de estudos, na tentativa de identificar os efeitos e os mecanismos de ação dos mesmos, afim de que estes medicamentos possam ser utilizados com segurança e com o menor efeito adverso possível.

PALAVRAS-CHAVE: Câncer. Fitoterapia. Potencial terapêutico. Substâncias bioativas. 


\title{
ANTINEOPLASTIC CHEMOTHERAPY DERIVED FROM PLANTS: LITERATURE REVIEW
}

\begin{abstract}
The main treatments against cancer are chemotherapy, radiation therapy, surgery, hormonal therapy and immunotherapy. Chemotherapy is the most used technique, and consists of the destruction of cancer cells, which is characterized by presenting a division faster than the division of a normal cell. However, it is still a technique that causes adverse effects on normal cells due to its high toxicity. There is a consensus among researchers and health professionals, it is necessary to use drugs that have greater efficiency and less adverse effects for the treatment of cancer. In this sense, several centers of excellence in research have sought the development of new chemotherapeutics from plants, currently $60 \%$ of the drugs used in clinical trials are derived from natural products. In view of the above, this literature review aimed to present the antineoplastic chemotherapy drugs derived from some plant species, which have been used in the treatment of cancer. They are paclitacel and docetaxel, vinblastine, vincristine, vindesine and vinorelbine, camptothecin, topotecan and irinotecan, podophyllotoxin, etoposide and teniposide, extracted from plants of the species Catharanthus roseus, Camptotheca accuminata, Taxus peliftatum, Podophyll. These compounds from natural sources are now frequently used in chemotherapy, however other compounds with promising properties in antineoplastic use are under study, in an attempt to identify their effects and mechanisms of action, so that these drugs can be used safely and with the least possible adverse effect.
\end{abstract}

KEYWORDS: Cancer. Phytotherapy. Therapeutic potential. Bioactive substances.

\section{INTRODUÇÃO}

A formação de uma nova célula acontece por meio da duplicação de uma célula pré-existente. O ciclo celular é o processo no qual o DNA é duplicado e a divisão celular (mitose) resulta na formação de uma nova célula. Essa reprodução envolve uma sequência organizada de eventos; porém, quando erros acontecem nesta sequência, um dos mecanismos de regulação deste DNA alterado é a morte celular programada denominada apoptose (TAKANA, 2013; TAKANA et al., 2013). Quando os mecanismos de regulação falham, o DNA alterado leva a formação de doenças como, por exemplo, o câncer (CHU; RUBIN, 2018).

Câncer é o nome dado a um conjunto de mais de 200 doenças, que têm em comum a agressividade causada pela desordem do ciclo celular e na multiplicação das células. O câncer atualmente é a principal causa de morte por doenças não transmissíveis em todo o mundo e assim se apresenta como um problema de saúde pública, tanto em países desenvolvidos como em países em subdesenvolvidos ou em desenvolvimento (MARZO-CASTILLEJO et al., 2016; ROKHFOROZ et al., 2017; INCA, 2018).

Os principais tratamentos contra o câncer são a quimioterapia, a radioterapia, cirurgia, terapia hormonal e imunoterapia (MILLER et al., 2016; ROKHFOROZ et al., 2017). A quimioterapia é a técnica mais utilizada, e consiste na destruição das células cancerígenas, que se caracterizam por apresentar uma divisão mais rápida que a divisão de uma célula normal (ROKHFOROZ et al., 2017). Porém, ainda é uma técnica que causa efeitos adversos em células normais devido à sua alta toxicidade. É consenso entre pesquisadores e profissionais de saúde que é necessário empregar medicamentos que apresentem maior eficiência e menor efeito adverso para o tratamento do câncer. Neste sentido, diversos centros de 
excelência em pesquisa têm buscado o desenvolvimento de novos quimioterápicos a partir de plantas, atualmente $60 \%$ das drogas utilizadas em ensaios clínicos são derivados de produtos naturais (ZILLA et al., 2014).

O uso de substâncias obtidas de fontes naturais no tratamento de enfermidades é prática comum desde a antiguidade (GIORDANI et al., 2015: SANTOS-LIMA et al., 2016: CONCEIÇÃO; AOYAMA, 2016) Um dos relatos mais antigos que se tem notícia da utilização de plantas para fins terapêuticos data de 3.000 a.C., na obra Pen Ts'ao, do chinês Shen Nung. Estima-se que medicamentos derivados de produtos naturais possam ser empregados como tratamento de $87 \%$ das doenças humanas (SIMÕES et al., 2016).

$\mathrm{Na}$ atualidade, diversos medicamentos utilizados na terapia de várias doenças são derivados direta ou indiretamente de fontes naturais como vegetais, micro-organismos, organismos marinhos, vertebrados e invertebrados terrestres (OWEN et al., 2017). Por seu potencial de apresentar efeitos colaterais mais brandos, essas substâncias se apresentam como promissoras alternativas à medicina tradicional, diante da tecnologia e diversidade de estratégias e métodos disponíveis para a descoberta de novos fármacos (AHMAD et al., 2017).

Os estudos com substâncias conhecidas como metabólitos secundários que são extraídas de plantas possibilitaram a descoberta de produtos químicos que possuem fundamental importância no tratamento de determinadas neoplasias. Dentre esses, encontram-se os quimioterápicos como a vincristina e a vimblastina, que foram isoladas da vinca (Catharanthus roseus); os derivados da podofilotoxina, procedidos de rizomas de Podophyllum peltatume $P$. hexandrum; os oriundos da camptotecina, obtidos da Campotheca acuminata; o taxol e o docetaxol extraídos de Taxus brevifolia e T. baccata (CHU; RUBIN, 2018).

Diante do exposto, esta revisão de literatura tem como objetivo apresentar os quimioterápicos antineoplásicos derivados de algumas espécies de plantas, os quais têm sido utilizados no tratamento do câncer.

\section{CÂNCER}

A palavra câncer, de origem latina, é a tradução do termo grego carcinoma, que significa caranguejo. Essa analogia foi utilizada pela primeira vez na antiga Grécia por Hipócrates, que associou a semelhança entre as patas do crustáceo e a vascularização em volta de um tumor. Descobertas em múmias egípcias demonstram que a doença já atingia o homem há mais de três mil anos antes de Cristo. Esta doença se caracteriza por uma proliferação desordenada de células, que possuem a tendência de invadir tecidos e órgãos vizinhos (MUKHERJEE, 2012; SAITO et al., 2015).

Mesmo com todos os avanços no tratamento, o câncer ainda é um problema de saúde pública, principalmente nos países em desenvolvimento, e é uma das maiores causas de morte em todo mundo (CHENG et al., 2016; VIEIRA et al., 2017; ZHANG et al., 2018). A publicação do Relatório Mundial de Câncer (World Cancer Report) de 2014 da International Agency for Researchon Cancer (IARC), pela Organização Mundial da Saúde (OMS), mostra que a estimativa de novos casos até 2025 é de 20 milhões. Estima-se que $80 \%$ desses casos ocorram entre a população dos países em desenvolvimento. No Brasil foram esperados no biênio 2018-2019 a incidência de 600 mil casos novos em cada ano (INCA, 2018).

O surgimento do câncer no organismo acontece a partir de mutações em genes essenciais ao funcionamento da célula, que de forma coletiva, contribuem para o desenvolvimento de tumores malignos (SIDDIQUI et al., 2015). Essas 
alterações mutagênicas podem propiciar às células neoplásicas propriedades como a autossuficiência em relação aos sinais de crescimento, a falta de sensibilidade a sinais que inibem o crescimento, evasão à apoptose, ilimitado potencial de replicação, angiogênese sustentada, invasão tecidual e metástase (LANDISPIWOWAR; IYER, 2014; SIDDIQUI et al., 2015).

Segundo o Ministério da Saúde (BRASIL, 2019), o processo que leva à formação do câncer recebe o nome de carcinogênese. Este processo ocorre de forma lenta e pode levar muitos anos para que um conjunto de células neoplásicas se torne um tumor detectável clinicamente. A carcinogênese consiste dos estágios de iniciação, promoção e progressão (SIDDIQUI et al., 2015).

$\mathrm{Na}$ iniciação, as células sofrem o efeito do agente carcinogênico ou "oncoindicador", que causa alteração em alguns genes. Nesse estágio, mesmo que a célula esteja geneticamente modificada, ainda não é possível à detecção clínica de um tumor. Este estágio pode ser facilitado quando houver suscetibilidade genética e/ou latência, tornando-se um risco para o desenvolvimento do câncer em uma fase tardia. Os agentes carcinogênicos ou "oncoindicadores" podem ser endógenos, quando se referem a herança genética, erros na replicação do DNA e alterações dos radicais livres durante o metabolismo celular; ou exógenos, quando relativos à radiação ionizante e agentes químicos cancerígenos (SAITO et al. 2016; LAl, 2019).

$\mathrm{Na}$ promoção, as células que foram alteradas geneticamente passam pelos efeitos dos agentes "oncopromotores" ou cancerígenos. Ao sofrer este processo, a célula vai se transformando lentamente e gradualmente em célula maligna. Para acontecer a transformação, é necessária a exposição longa e continuada ao agente carcinogênico promotor. Caso seja suspenso o contato com este agente, ainda pode ocorrer a interrupção do processo carcinogênico nesse estágio (SAITO et al., 2016).

$\mathrm{Na}$ progressão, ocorre o descontrole durante a multiplicação celular. Esta etapa é irreversível, ou seja, a neoplasia maligna está instalada e as manifestações clínicas da doença começam a surgir. $\mathrm{Na}$ fase de progressão ocorre a perda da sensibilidade aos sinais que inibem a proliferação, em função das alterações que ocorrem nos mecanismos regulatórios que controlam a multiplicação celular (SAITO et al., 2016).

Células normais necessitam de sinais mitogênicos de crescimento e, assim, passam do estado quiescente para a proliferação ativa. A sinalização é transmitida para o interior da célula através de receptores transmembrana, que ativam diferentes classes de moléculas, como fatores de crescimento, componentes da matriz extracelular e moléculas de adesão (DE PALMA et al., 2017). A aquisição de autonomia de sinais de crescimento foi a primeira capacidade adquirida pela célula com tumor, a ser definida de forma clara pelos pesquisadores em câncer (RAK et al., 1995). Três estratégias moleculares comuns para a autonomia envolvem alterações em sinais de crescimento extracelulares, em transdutores transcelulares da sinalização, ou de circuitos intracelulares que traduzem estes sinais em ação (RAK et al., 1995).

Os diferentes tipos de câncer são classificados de acordo com o tipo de tecido onde se originam. Se são derivados dos tecidos epiteliais, a neoplasia é denominada carcinoma, tipo de câncer mais comum em humanos. Caso seja originada de tecido mesenquimal, recebe o nome de sarcoma. Quando se inicia no sistema linfático, é denominado linfoma e há ainda a leucemia, que é a neoplasia maligna da medula óssea (SAITO et al., 2016).

Os tipos principais de tratamento para o câncer são a quimioterapia, a radioterapia, cirurgia, terapia hormonal e imunoterapia (MILLER et al., 2016; 
ROKHFOROZ et al., 2017). A quimioterapia consiste na destruição das células cancerígenas, que se caracterizam por apresentarem uma divisão com rapidez maior que a células com divisão normal. Porém, este tipo de tratamento apresenta constantemente efeitos adversos em células normais, principalmente gastrointestinais, capilares e do sistema imunológico (RAK et al. 1995; ALMEIDA et al., 2005; CHU; RUBIN, 2018).

Os fármacos quimioterápicos mais utilizados no tratamento do câncer humano são: mercaptopurina, tioguanina (antimetabólitos que causam principalmente a inibição da síntese das purinas), hidroxiureia, fluruoracila (agem inibindo que formem os dexorribonucleotídeos), Cisplatina (modificação do DNA por alquilação), bleomicina, daunorrubicina, doxorrubicina, etoposídeo (interação com topoisomerase II), actinomicina D, vincristina e vimblastina (inibe a síntese do RNA ou de proteínas) etaxanos (interação com a tubulina) (CHU; RUBIN, 2018) (Figura 1).

A estratégia preferencial das terapias antineoplásicas consiste na associação de fármacos quimioterápicos, apresentando alta incidência de reações adversas em decorrência da alta toxicidade. Ainda, a diminuição da eficácia da terapia associativa contra as neoplasias pode ocorrer pela resistência a multifármacos (multidrugresistence - MDR). A multirresistência acontece quando a célula com câncer fica protegida da ação tóxica dos fármacos quimioterápicos. A MDR ocorre frequentemente, fazendo com que seja necessária a indicação de terapias associadas de mais de um fármaco (LI et al., 2017).

FIGURA 1 - Esquema representando atividade dos agentes quimioterápicos antineoplásicos dependendo da fase do ciclo celular.

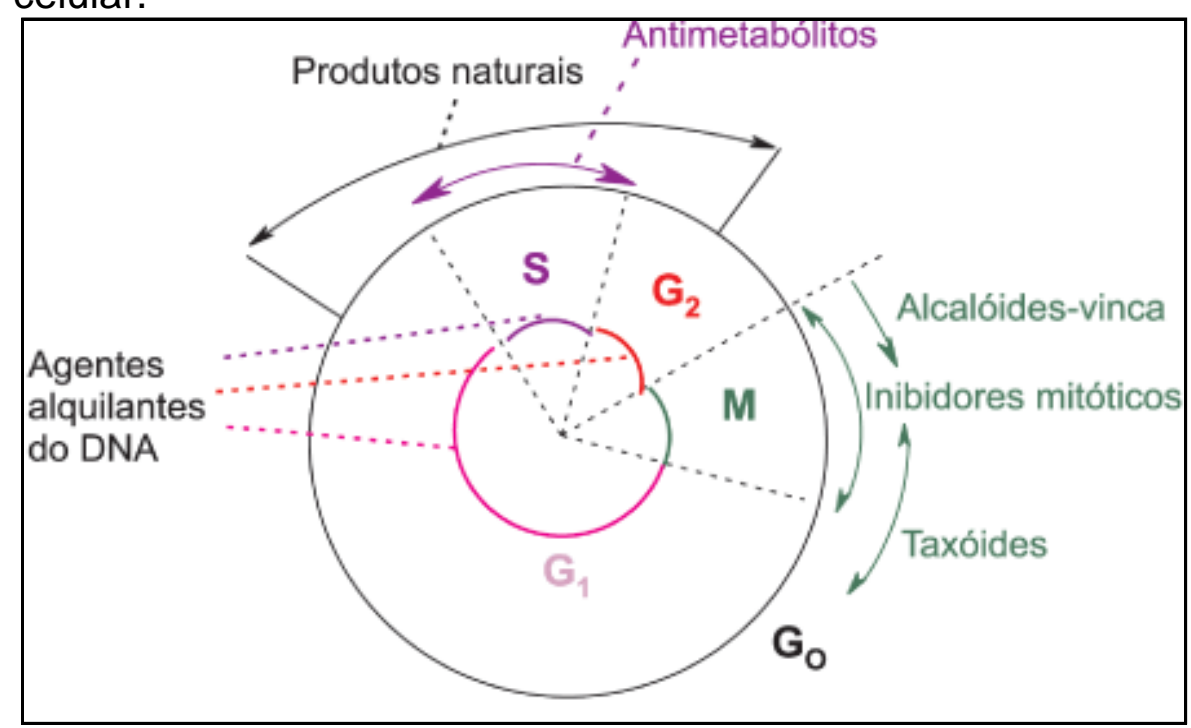

Fonte: ALMEIDA et al., (2005).

As estratégias para descoberta de novos fármacos antineoplásicos tem sofrido uma alteração notável que acontece devido às elucidações da base molecular para transformação da célula normal em célula cancerosa. Conhecer a biologia do câncer tem possibilitado a descoberta de alvos específicos como os receptores de fatores de crescimento, vias de sinalização intracelulares, processos epigenéticos, vascularidades dos tumores, defeitos no reparo do DNA e vias de morte celular. Por exemplo, vários tumores possuem a proliferação e a sobrevida 
dependente de uma única via de fatores de crescimento, assim inibindo essa via específica ocorrerá a morte celular (WEINSTEIN; JOE, 2006; BRUNTON et al., 2019).

A fotorradiação e a imunoterapia são técnicas antineoplásicas também muito utilizadas, em associação a uma das terapias supracitadas. A fotorradiação com derivados hematoporfirínicos (HTP) apresenta a vantagem de selecionar melhor a célula a ser destruída, porém ela não pode ser utilizada internamente, somente em tumores que são superficiais, pois pode haver acumulação de porfirinas nos órgãos sadios. A imunoterapia estimula as defesas do organismo com interleucina-2, interferon $\alpha$, e ainda o Bacilo Calmette-Guérin (BCG), técnica utilizada principalmente para destruir células neoplásicas remanescentes de cirurgias $(\mathrm{CHU}$; RUBIN, 2018; LI et al., 2019, LE et al., 2019).

É consenso entre pesquisadores e profissionais de saúde, que é necessário empregar medicamentos que apresentem maior eficiência e menor efeito adverso para o tratamento do câncer. Neste sentido, diversos centros de excelência em pesquisa têm buscado o desenvolvimento de novos quimioterápicos a partir de plantas (CASANOVA; COSTA, 2017). Já que diversos fitoquímicos podem apresentar atividade antiproliferativa, inativando os eletrófilos reativos que apresentam potencial carcinogênico e eliminando espécies reativas de oxigênio que poderão dar início à carcinogênese (JENDIROBA et al., 2002: MEYERS et al., 2003; CHENG et al., 2016). Para investigar se o fitoquímico pode potencialmente destruir uma célula com câncer, são realizados testes de citotoxicidade em linhagens neoplásicas em cultura, onde o fitoquímico é colocado em contato direto com a cultura celular, observando-se a possível apoptose da célula (SACOMAN et al., 2007).

A atividade antiproliferativa é parâmetro para que seja detectada atividade antitumoral (SACOMAN et al., 2007). Para avaliação desta atividade, são realizados ensaios utilizando metodologias como contagem celular, ensaios clonogênicos, e medida de incorporação de nucleotídeos radioativos ou métodos colorimétricos (HENRIKSSON et al., 2006). A maioria dos métodos colorimétricos avalia a taxa de crescimento e multiplicação, de forma indireta, por algum indicador de crescimento por meio da revelação da coloração (SIMÕES et al., 2016).

\section{METABOLISMO SECUNDÁRIO DAS PLANTAS}

Metabolismo é o conjunto de reações químicas que ocorre ininterruptamente em cada célula. Essas reações visam, primariamente, o aproveitamento de nutrientes para satisfazer as exigências fundamentais das células (SIMÕES et al., 2016). As plantas continuamente produzem muitos componentes orgânicos, que são classificados em metabólitos primários e secundários. Para sua sobrevivência, as plantas realizam o processo denominado fotossíntese, no qual a energia luminosa é transformada em energia química, utilizando a energia do sol para oxidar água, fazer a liberação de oxigênio, produzir dióxido de carbônico e compostos orgânicos como glicose e outros carboidratos. Estes compostos são chamados de metabólitos primários orgânicos, formando o conjunto de processos metabólicos que desempenham uma função essencial à vida do organismo produtor. São usados como fonte de energia na respiração, no crescimento e como precursores na síntese por meio de reações enzimáticas de outros compostos e do metabolismo secundário (TAIZ; ZEIGER, 2004; SIMÕES et al., 2016).

O metabolismo secundário pode ser definido como conjunto metabólico cujos produtos não são essenciais à vida do produtor e que garantem vantagens na 
sobrevivência e na perpetuação da espécie, em seu ecossistema. É um arsenal de metabólitos como enzimas e coenzimas, que tem a capacidade de produção, transformação e acumulação de inúmeras substâncias. Estas substâncias exercem funções como defesa contra herbívoros e micro-organismos, proteção contra radiação ultravioleta (UV), competição entre plantas, atração de polinizadores ou animais dispersores de sementes. Outras características interessantes do metabolismo secundário é a alta capacidade biossintética, tanto relacionada com a quantidade de substâncias produzidas quanto na variedade numa mesma espécie (GOBBO-NETO; LOPES 2007).

A disponibilidade dos metabólitos pode ser alterada pelo ritmo circadiano da sua biossíntese, por ser diretamente ligado pela interação entre a planta e meio em que vive. Haverá variações decorrentes de fatores como o desenvolvimento da planta, temperatura, altitude, índice pluviométrico, raios UV, macro e micronutrientes, condições ecológicas ou ambientais, estímulos mecânicos ou ataque de patógenos. Por outro lado, resultados de análises laboratoriais de metabólitos podem sofrer a influência dos métodos de coleta, estabilização e estocagem (GOBBO-NETO; LOPES, 2007; SIMÕES et al., 2016: JESUS et al., 2016).

Os metabólitos secundários nas plantas são classificados em três grandes grupos: terpenos, compostos fenólicos e alcalóides. Os terpenos derivam do isopreno e são produzidos a partir do ácido mevalônico ou do piruvato e 3fosfoglicerato. Os compostos fenólicos derivam do ácido chiquímico ou do ácido mevalônico. Os alcaloides, por sua vez, se originam de aminoácidos, como os aromáticos (triptofano, tirosina) derivados do ácido chiquímico, ou podem ter sua biossíntese mediada por aminoácidos alifáticos (GOBBO-NETO; LOPES, 2007; SIMÕES et al., 2016).

FIGURA 2 - Esquema do ciclo biossintético dos metabólitos secundários dos vegetais.

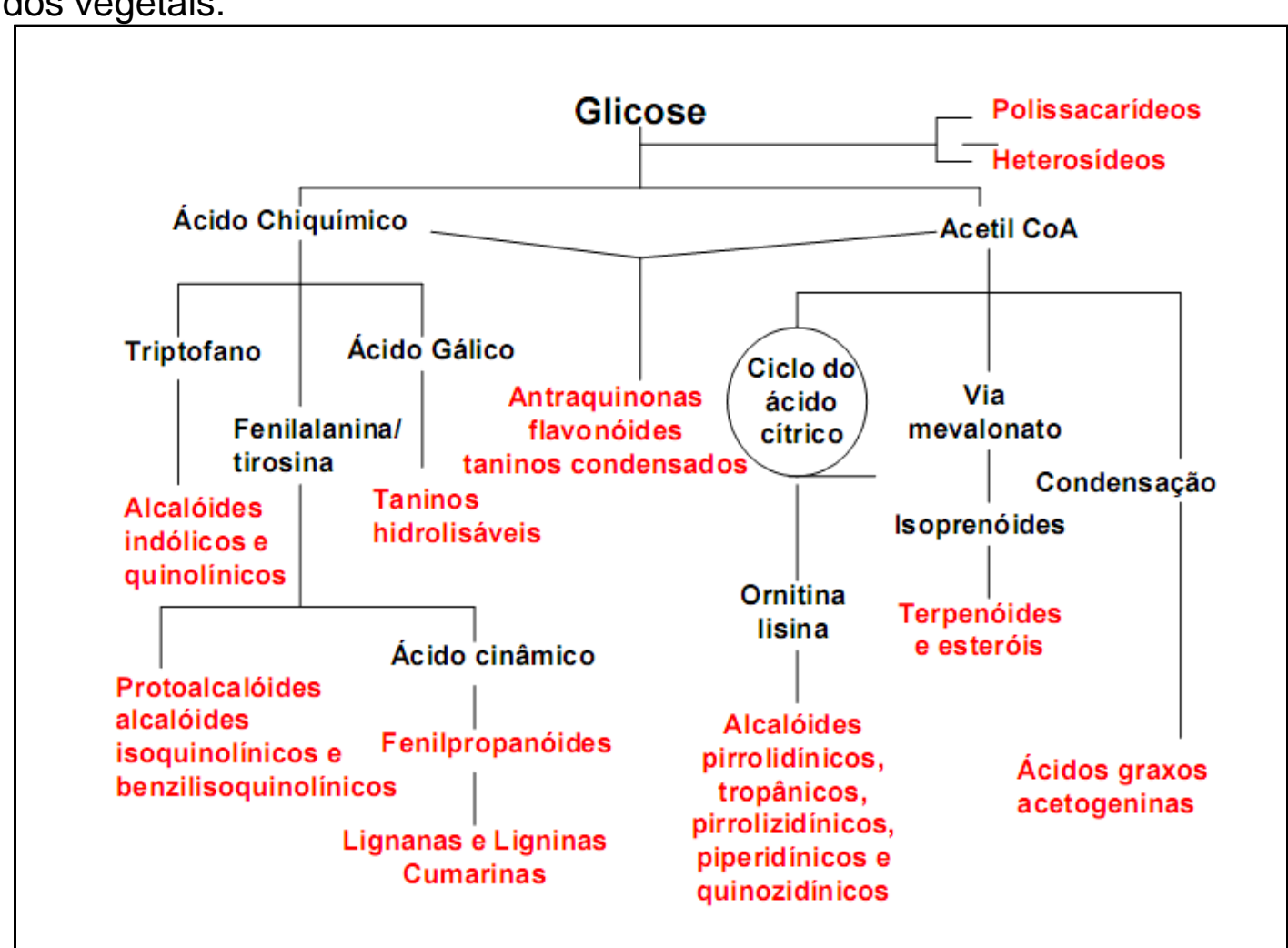

Fonte: SIMÕES et al. (2016). 
Os terpenos estão presentes nos óleos essenciais, que são conhecidos também como óleos voláteis ou etéreos por evaporar rápido quando exposto ao ar. Os óleos essenciais são encontrados em diversas partes da planta e são eles que conferem o odor característico dos vegetais. Nas plantas eles servem para atrair polinizadores e também como repelente de insetos e herbívoros. Entre as propriedades medicinais estão: uso como antisséptico, anti-inflamatório e antipirético (SIMÕES et al., 2016).

Além dos aminoácidos, outros percussores como os terpenos esteroides participam da formação da estrutura final dos alcaloides. Estes podem ser encontrados em qualquer parte da planta e estão presentes em representantes de todos os grupos vegetais, porém sua maior ocorrência é nas angiospermas (FELIPE; BICAS, 2017). Plantas produtoras de alcaloides são evitadas na dieta de animais e insetos e são repelidas por herbívoros, provavelmente devido à toxicidade ou ao gosto amargo da maioria dos alcaloides. Ainda assim, são utilizados por determinado grupo de borboletas para defesa contra predadores, e até como síntese de feromônios por aranhas. Uma possível função deste metabólito para o vegetal seria proteção contra irradiação UV, pois seu núcleo aromático possui alta capacidade de absorção dessa radiação (SIMÕES et al., 2016).

Diversos alcaloides são utilizados na terapêutica, puros, em associação e como matéria-prima para a síntese de fármacos. Como exemplo de maior importância nesse grupo podem ser citados os alcaloides da vinca (Catharanthus roseus) como a vincristina e vimblastina, que são utilizados como antineoplásicos (TAIZ; ZEIGER, 2004).

Os flavonoides são os que estão presentes em maior abundância entre os metabólitos, sendo conhecidos mais de 6.000 flavonoides diferentes. São formados pela combinação de uma unidade de ácido chiquímico e uma ou mais unidades de acetato ou derivados deste, por biossíntese mista. São responsáveis pela proteção das plantas contra o UV, insetos, fungos, vírus e bactérias, além de controle da ação dos hormônios vegetais. A proteção contra a foto destruição proporcionada por esses compostos ocorre devido às suas propriedades de absorver e dissipar a energia solar. Os flavonoides que são encontrados nas folhas podem ser diferentes dos presentes nas demais partes da planta. Este metabólito apresenta propriedades medicinais como: anticarcinogênico, anti-inflamatório, antialérgico, antiulcerogênico, antitrombótica, vasoprotetora e antivirais (GOBBO-NETO; LOPES, 2007; SIMỖS et al., 2016).

\section{QUIMIOTERÁPICOS ANTINEOPLÁSICOS DERIVADOS DE PLANTAS}

A história mostra que, desde a antiguidade, o homem sempre procurou na natureza uma forma de curar suas doenças (IJAZ et al., 2018). O reino vegetal, por possuir uma variedade vasta de espécies, é a fonte principal de recursos de pesquisa de novos possíveis fármacos. O tratamento e cura das enfermidades utilizando plantas são muito utilizados pelo conhecimento etnofarmacológico como cultura passada ao longo das gerações, no entanto esse cabedal de informações ainda é pouco explorado pela comunidade científica. Muito deste conhecimento se perde e, junto a isso, a possível cura de muitas doenças (MACHADO et al., 2004).

Segundo Newman et al., (2003), medicamentos derivados de recursos naturais podem tratar $87 \%$ das enfermidades em humanos, incluindo o tratamento do câncer. Centros de pesquisas de excelência como o Instituto Nacional do Câncer (NCl), nos Estados Unidos, tem buscado desde 1983 compostos ativos para desenvolver fármacos antineoplásicos. 
A busca por novos medicamentos é importante e cada vez mais intensa, pois ainda não há um tratamento efetivo que seja seletivo. É necessário inovar nas estratégias de impedimento do avanço do câncer, por meio da seleção de moléculas que possuam mecanismo específico para cada tipo de neoplasia (GREENWELL; RAHMAN, 2015). Extratos obtidos de plantas, que apresentam uma variedade de moléculas que atuam por diversos mecanismos, têm sido progressivamente úteis como terapia anticâncer (AQIL et al., 2019).

O quadro 1 apresenta os fármacos, a espécie fonte de onde o fármaco é derivado e a indicação terapêutica de cada um destes medicamentos quimioterápicos. Em seguida, as plantas, seus metabólitos e efeitos conhecidos serão descritos em detalhes.

QUADRO 1 - Quimioterápicos neoplásicos mais utilizados no tratamento de câncer.

\begin{tabular}{|c|c|c|}
\hline FÁRMACO & ESPÉCIE & INDICAÇÃO TERAPÊUTICA \\
\hline $\begin{array}{l}\text { Paclitacel e } \\
\text { docetaxel }\end{array}$ & Taxus brevifolia & $\begin{array}{l}\text { Câncer de mama e ovário, pulmão de não } \\
\text { pequenas células, cabeça, pescoço, e como } \\
\text { tratamento de segunda linha para sarcoma } \\
\text { de Kaposi. Tratamento padrão utilizado } \\
\text { combinado com outros quimioterápicos como } \\
\text { cisplatina e carboplatina, em casos que } \\
\text { evoluíram para metástase que não podem } \\
\text { passar por intervenção cirúrgica e o } \\
\text { tratamento padrão com platina não } \\
\text { funcionou. }\end{array}$ \\
\hline $\begin{array}{l}\text { Vimblastina, } \\
\text { vincristina, } \\
\text { vindesina e } \\
\text { vinorelbina. }\end{array}$ & $\begin{array}{l}\text { Catharanthus } \\
\text { roseus }\end{array}$ & $\begin{array}{l}\text { Câncer de testículos, bexiga, linfoma, mama, } \\
\text { sarcoma de Kaposi, cérvico-uterino, linfomas } \\
\text { não-Hodgkin, linfoma Hodgkin, leucemia } \\
\text { aguda, pulmão e como coadjuvante no } \\
\text { tratamento de rabdomiosarcoma, } \\
\text { neuroblastoma e nefroblastoma. }\end{array}$ \\
\hline $\begin{array}{l}\text { Camptotecina, } \\
\text { topotecano e } \\
\text { irinotecano. }\end{array}$ & $\begin{array}{l}\text { Camptotheca } \\
\text { accuminata }\end{array}$ & $\begin{array}{l}\text { Câncer de pulmão de não pequenas células } \\
\text { e de células pequenas, ovário, colo de útero, } \\
\text { câncer metastático de ovário, cerebral e } \\
\text { colorretal. }\end{array}$ \\
\hline $\begin{array}{l}\text { Podofilotoxina, } \\
\text { Etoposídeo e } \\
\text { teniposídeo. }\end{array}$ & $\begin{array}{l}\text { Podophyllum } \\
\text { peltatum }\end{array}$ & $\begin{array}{l}\text { Nefroblastoma, carcinomas de } \\
\text { genitais (carcinoma verrucoso), testículo, } \\
\text { linfomas não-Hodgkin e } \\
\text { linfoblástica aguda em crianças. }\end{array}$ \\
\hline
\end{tabular}

\section{Taxus brevifolia}

Conhecida popularmente como teixo do pacífico ou teixo ocidental, a Taxus brevifolia, que pertence à família Taxaceae, é encontrada do Alasca à Califórnia, nos Estados Unidos. Odiperteno e placlitaxel $\left(\right.$ Taxol $\left.^{\circledR}\right)$ foram isolados e identificados em extratos da casca do caule desta espécie em 1971. Pesquisas clínicas demonstraram que os compostos isolados eram capazes de promover regressão no câncer de mama e de ovário, que resistem as terapias tradicionais (THURSTON, 2006; CHU; RUBIN, 2018). 
Atualmente, além de ser utilizado no câncer de mama e ovário, atua no tratamento de câncer de pulmão de não pequenas células, cabeça e pescoço. Também é empregado no sarcoma de Kaposi como tratamento de segunda linha, ou seja, quando o tratamento inicial não condiz com o resultado esperado (LIU et al., 2020; KURIAKOSE et al., 2020) 'Esta substância é administrada por via intravenosa, combinada com outros quimioterápicos como cisplatina e carboplatina, em casos que evoluíram para metástase, onde não pode haver intervenção cirúrgica e o tratamento padrão com platina não demonstrou eficiência (THURSTON, 2006).

O mecanismo de ação do paclitaxel ocorre quando ele se liga de forma específica e reversível à subunidade $\beta$ da tubulina e assim promove a sua polimerização provocando a estabilização dos microtúbulos. O resultado da estabilização é bloqueio do ciclo celular na fase $\mathrm{G} 2 / \mathrm{M}$, inibindo a mitose, e levando a célula a morte por apoptose (NOBILI et al., 2009: BRANDÃO et al., 2010). paclitaxel induz a morte celular no câncer de mama, por exemplo, utilizando a via intrínseca. A drogas que utilizam esta via induzem a morte com o aumento do equilíbrio das proteínas pró-apoptóticas em relação as proteínas anti-apoptóticas (FUNATO et al., 2012).

Estudos sobre apoptose em uma linhagem de câncer de próstata (PC-3) demonstraram que pré-tratamento destas células com paclitaxel induz a expressão de morte pelos receptores DR4/DR5 elevando a morte induzida por TRAIL (via extrínseca), porém quando tratada apenas com paclitaxel foi observado que a via de indução a morte era mitocondrial, ou seja, intrínseca (NINMANAPALLI et al., 2001).

\section{Catharanthus roseus}

A espécie Catharanthus roseus, pertencente à família Apocynaceae e nativa de Madasgascar, é encontrada no mundo todo e utilizada comumente como planta ornamental (FARINACCIO; SIMÕES, 2018). Suas atividades antiproliferativas foram descobertas por dois grupos de pesquisas diferentes na década de 1950. Nas partes aéreas destas plantas, foram encontrados mais de 100 compostos, sendo taninos e alcaloides os principais metabólitos secundários descritos (QU et al., 2019).

Esses alcaloides, atualmente denominados alcaloides da vinca, apresentam importante impacto terapêutico e consequentemente econômico, podendo ser citados, dentre outros, a vinblastina, vincristina, vindesina, vinorelbina (semisintética) e vinflunina, todos utilizados no tratamento do câncer (QU et al., 2019).

Os diversos alcaloides derivados de $C$. roseus possuem estruturas semelhantes, porém a toxicidade e a atividade são diferentes entre si. A vimblastina é mais efetiva no tratamento de câncer de testículos, bexiga, linfoma, mama ou sarcoma de Kaposi e cérvico-uterino. A vincristina é indicada para linfomas não-Hodgkin, linfoma Hodgkin, leucemia aguda, e como coadjuvante no tratamento de rabdomiosarcoma, neuroblastoma e nefroblastoma. A vinorelbina é utilizada no câncer de pulmão e mama (SCHNEIDER et al., 2017). A vincristina é um antimitótico que atua especificamente durante a mitose e a interfase, impedindo a divisão mitótica durante a metáfase ao se ligar a tubulina, impede então a polimerização e a formação de microtúbulos do feixe mitótico. Interfere na síntese protéica e de ácidos nucléicos bloqueando a utilização do ácido glutâmico. A morte celular acontece devido a interrupção da mitose (BRANDÃO et al. 2010). 


\section{Camptotheca acuminata}

Da família Nyssaceae, a espécie Camptotheca acuminata, é nativa do Tibet e do Sul da China. Os estudos com esta planta tiveram início na década de 1950. Em 1958, do extrato da casca e da madeira do caule, foi isolado o alcaloide camptotecina, com ação anticâncer (SUN et al., 2019). Para minimizar seus efeitos tóxicos colaterais, a camptotecina foi semi-sintetizada em irinotecano, que foi sintetizado em topetecano. Desde 1996, o irinotecano é utilizado no tratamento de câncer de pulmão de não pequenas células e de células pequenas, ovário e colo de útero, além de um pró medicamento combinado com fluorouracil e oxaliplatina em caso de metástase de câncer coloretal. O topotecano é utilizado em câncer de pulmão de pequenas células, do colo do útero, e de câncer metastático de ovário e cerebral (ZHAO et al. 2017).

As camptotecinas atuam inibindo ineficazmente a topoisomerase I (enzima que repara os filamentos quebrados do DNA e permite a duplicação ou transcrição), seu efeito citotóxico é a reparação que ocorre de forma ineficiente no dano produzido na dupla cadeia do DNA (CARVALHO et al., 2008).

\section{Podophyllum peltatum}

A planta herbácea da espécie Podophyllumpeltatum, da família Berberidaceae, conhecida popularmente como Mayflower ou Mandrake, é nativa do leste da América do Norte (NORBERT, 2016). Esta planta possui uma resina rica em podofilotoxina, que apresenta moderada ação antitumoral. Em razão dos seus efeitos tóxicos, foram sintetizados, a partir desse composto, dois fármacos semisintéticos, o teniposídeo e o etoposídeo, que possuem maior ação anticâncer que a podofilotoxina. Esta é usada no tratamento de nefroblastoma, carcinomas de pulmão, genitais (carcinoma verrucoso) e linfomas não-Hodgkin. O teniposídeo é utilizado na terapia de leucemia linfoblástica aguda em crianças quando existe ineficiência de outros tratamentos. O etoposídeo é usado como anticâncer de pulmão, testículos, mama, doença de Hodgking, linfomas não Hodgkin, leucemia mielógena aguda, sarcoma kaposi (TUGBOBO et al., 2020).

$\mathrm{O}$ etoposídio age inibindo a mitose das células na prófase. Forma complexo ternário com a enzima topoisomerase II e DNA, causando a quebra da dupla hélice de DNA. Inibindo a topoisomerase, acumulando quebras do DNA e morte celular. A maior sensibilidade ocorre nas fases S e G2 do ciclo celular. O teniposídeo bloqueia a ação da topoisomerase II. As células necessitam dessa enzima para manter o DNA sob forma adequada quando se dividem em células filhas. $O$ bloqueio dessa enzima leva a quebra do DNA, ocasionando a morte celular (CHEN et al., 2020).

\section{CONSIDERAÇÕES FINAIS}

Substâncias de fontes naturais são utilizadas no tratamento de enfermidades desde tempos imemoriais, muitos dos medicamentos encontrados no mercado hoje são derivados de forma direta ou indireta de fontes orgânicas. Os vegetais são as maiores fontes de substâncias ativas com potencial terapêutico, devido a quantidade de metabólitos e possivelmente foi a fonte mais antiga de busca pelo homem para a cura de doenças.

O ciclo celular é um evento onde ocorre a duplicação das células, este evento garante a homeostase dos seres vivos, sendo ele o responsável pelo crescimento e desenvolvimento. Esta multiplicação celular ocorre em uma sequência organizada de eventos onde uma célula se divide em duas com características genéticas idênticas. Quando algum erro acontece nesta sequência de eventos 0 
ciclo celular é alterado e pode ocorrer o surgimento de várias doenças entre elas o câncer.

O câncer é uma doença caracterizada pela proliferação descontrolada da célula é uma das doenças que causam maior temor na sociedade por ter um estigma de morte e dor relacionada a ela. Apesar do câncer ser conhecido há séculos, eram poucas as informações sobre os mecanismos biológicos e de como acontecia o progresso do tumor até a última metade do século $X X$, quando se iniciou os estudos de biologia molecular.

Em 1960 o Instituto Nacional do Câncer dos Estados Unidos (NCI), começou a estudar plantas que poderiam possuir potenciais antineoplásicos, estes estudos propiciaram a avaliação dos metabólitos secundários destas plantas e foram descobertas atividades citotóxicas contra o câncer.

Os primeiros antitumorais derivados de plantas a serem identificados foram a vimblastina e a vincristina que foram isoladas da Catharanthus roseus G. Don. Após a identificação dos compostos supracitados outros compostos e derivados foram identificados e começaram a ser utilizados para melhora da eficácia de quimioterápicos.

De espécies do gênero Podophyllum houve o isolamento da pofiloxina. Derivados do gênero Taxus foram mais recentemente colocados na lista de agentes quimioterápicos, há ainda a elipticina derivada de várias espécies da família Apocynaceae.

Estes compostos de fontes naturais são hoje empregados com frequência na quimioterapia, porém outros compostos com propriedades promissoras na utilização antineoplásica estão em fase de estudos tentando identificar os efeitos e os mecanismos de ação dos mesmos, afim de que estes medicamentos possam ser utilizados com segurança e com o menor efeito adverso possível.

\section{REFERÊNCIAS}

AHMAD, R.; AHMAD, R., AHMAD, N., NAQVI, A. A., SHEHZAD, A., \& AL-GHAMDI, M. S. Role of traditional Islamic and Arabic plants in cancer therapy. Journal of traditional and complementary medicine, v. 7, n. 2, p. 195-204, 2017. Disponível em: https://doi.org/10.1016/j.jtcme.2016.05.002.

ALMEIDA V. L.; LEITÃO A.; REINA L. C.B.; MONTANARI C. A.; DONNICI C. L.; LOPEZ M. T. P. Câncer e agentes antineoplásicos ciclo-celular específicos e ciclocelular não específicos que interagem com o DNA: uma introdução. Revista Química Nova, 2005; 28: 118. Disponível em: http://dx.doi.org/10.1590/S010040422005000100021.

AQIL, F., MUNAGALA, R., AGRAWAL, A. K., \& GUPTA, R. Anticancer Phytocompounds: Experimental and Clinical Updates. In New Look to Phytomedicine (pp. 237-272). Academic Press. Anticancer Phytocompounds: Experimental and Clinical Updates. In: New Look to Phytomedicine. Academic Press, 2019. p. 237272. Disponível em: https://doi.org/10.1016/B978-0-12-814619-4.00010-0.

BRANDÃO H.; DAVID J. P.; COUTO R. D.; NASCIMENTO J. A. P.; DAVID J. M. Química e farmacologia de quimioterápicos antineoplásicos derivados de plantas. Revista Virtual Química Nova, v. 6 n. 33, p. 1359-1369, 2010. http://dx.doi.org/10.1590/S0100-40422010000600026. 
BRASIL, Ministério da Saúde. Câncer: O que é, Causas, Tipos e Sintomas. Brasília - DF, 2019. Disponível em: http://www.saude.gov.br/saude-de-a-z/cancer Acesso em 04 agosto 2020

BRUNTON, L. L.; CHABNER, B. A.; KNOLLMANN, B. C. As Bases Farmacológicas da Terapêutica de Goodman \& Gilman-12. AMGH Editora Ltda. 2019. Disponível em:

https://books.google.com.br/books?id=9WuADwAAQBAJ\&lpg=PR1\&ots=bXnvnB. Acesso em 15 julho 2020.

CARVALHO V. A.; FRANCO M. H.; KOVÁCS M. J.; LIBERATO R. P.; MACIEIRA R. C.; VEIT M. T.; GOMES M. J. B.; BARROS L. H. C. Temas em psicooncologia. São Paulo: Summus. $2008 . \quad 9 p . \quad$ Disponível em: https://books.google.com.br/books?id=YWOleiAUmIQC\&lpg=PA5\&ots=loukcWPRyn.

CASANOVA, L. M.; COSTA, S. S. Interações sinérgicas em produtos naturais: potencial terapêutico e desafios. Revista Virtual de Química, v. 9, n. 2, 2017. Disponível em: http://rvq.sbq.org.br/detalhe_artigo.asp?id=745.

CHEN, H.; ZHANG, M.; WANG, Z.; LI, L.; LI, Q. e WANG, H. O efeito de p53-R249S na supressão da sobrevivência de células de carcinoma hepatocelular induzida por derivados de Podophyllum. Agentes Anti-Câncer em Química Medicinal (Anteriormente Agentes Químicos-Anti-Câncer Medicinais Atuais), v. 20, n. 7, p. 865-874, 2020. Disponível em: https://europepmc.org/article/med/32067620/ DOI: 10.2174 / 1871520620666200218110047.

CHENG, T. Y. D., CRAMB, S. M., BAADE, P. D., YOULDEN, D. R., NWOGU, C., \& REID, M. E. The international epidemiology of lung cancer: latest trends, disparities, and tumor characteristics. Journal of Thoracic Oncology, v.11, n.10, p.1653-1671, 2016. Disponível em: http://doi.org/10.1016/j.jtho.2016.05.021.

CHU C. S.; RUBIN S. C. Princípios básicos da quimioterapia. In: Di Saia PJ, Creasman WT, Mannel RS, McMeekin DS, Mutch DG, editores. Oncologia ginecológica clínica. 9a ed. Filadélfia, PA: Elsevier; pp. 449-469. 2018.

CONCEIÇÃO, L. O.; AOYAMA, E. M. Leaf anatomy and histochemistry of species known as stonebreaker (Euphorbia prostrata Aiton, Euphorbia hyssopifolia L., Phyllanthus amarus Schumach. \& Thonn, and Phyllanthus tenellus Roxb.). Revista Brasileira de Plantas Medicinais, v. 18, n. 2, p. 571-581, 2016. Disponível em: http://dx.doi.org/10.1590/1983-084x/15_226.

DE PALMA M.; BIZIATO D.; PETROVA T. V. Microenvironmental regulation of tumour angiogenesis. Nature Reviews Cancer, v. 17 n. (8), p. 457-74, 2017. Disponível em: https://doi.org/10.1038/nrc.2017.51

FARINACCIO, M. A.; SIMÕES, A. O. Check-list das Apocynaceae do estado de Mato Grosso do Sul, Brasil. Iheringia. Série Botânica., v. 73, p. 131-146, 2018. Disponível em: https://isb.emnuvens.com.br/iheringia/article/view/687. 
FELIPE, L. O.; BICAS, J. L. Terpenos, aromas e a química dos compostos naturais. Química Nova na Escola, v. 39, n. 2, p. 120-130, 2017. Disponível em: http://dx.doi.org/10.21577/0104-8899.20160068.

FUNATO M.; FUKAO T.; SASAI H.; HORI T.; TERAZAWA D.; KANDA K.; OZEKIM, M. K.; HIROSEY, K. H.; KONDO N.; IRISHMD, F. R. Paclitaxel-based chemotherapy for agressive kaposiform hemangio endothelioma of the temporomastoid region: case report and review of the literature. Head Neck. 2012; 35(8) E258-E261. Disponível em: https://doi.org/10.1002/hed.23107.

GREENWELL, M.; RAHMAN, P. K. S. M. Medicinal plants: their use in anticancer treatment. International journal of pharmaceutical sciences and research, v. $6, \mathrm{n}$. 10, p. 4103, 2015.

GIORDANI, C.; SANTIN, R.; CLEFF, M. B. Survey of plant extracts with anti-Candida activity in the 2005-2013 period. Revista Brasileira de Plantas Medicinais, v. 17, n. 1, p. 175-185, 2015. Disponível em: http://dx.doi.org/10.1590/1983-084X/12_072.

GOBBO-NETO L.; LOPES N. P. Plantas Medicinais: Fatores de Influência no Conteúdo de Metabólitos Secundários. Química Nova. 2007; 30(2): 374-381. Disponível em: https://doi.org/10.1590/S0100-40422007000200026.

HENRIKSSON E.; KJELLEN E.; WAHLBERG P.; WENNERBERG J.; KJELLSTROM J. $\mathrm{H}$. Differences in estimates of cisplatininduced cell kill in vitro between colorimetric and cell count/ colony assays. In Vitro Cellular \& Developmental Biology - Animal. 2006; 42:320-323. Disponível em: https://doi.org/10.1290/0604022.1.

IJAZ, S.; AKHTAR, N.; KHAN, M. S.; HAMEED, A.; IRFAN, M.; ARSHAD, M. A.; \& ASRAR, M. S. et al. Plant derived anticancer agents: A green approach towards skin cancers. Biomedicine \& Pharmacotherapy, v. 103, p. 1643-1651, 2018. https://doi.org/10.1016/j.biopha.2018.04.113.

INCA - Instituto Nacional de Câncer/Ministério da Saúde. Estimativa 2018: incidência de câncer no Brasil / Instituto Nacional de Câncer. José Alencar Gomes da Silva - Rio de Janeiro: INCA, 2018. Disponível em: http://www1.inca.gov.br/estimativa/2018/introducao.asp. Acesso em 10 julho 2020.

JENDIROBA D. B.; KLOSTERGAARD J.; KEYHANI A; PALIARO L.; FREIREICH E. $\mathrm{J}$; Effective cytotoxicity against human leukemias and chemotherapy-resistant leukemia cell lines by N-N-dimethylsphingosine. Leukemia Research. 26: 301-310. 2002. Disponível em: https://doi.org/10.1016/S0145-2126(01)00129-1.

JESUS, A. S. D.; BLANK, A. F.; ALVES, M. F.; ARRIGONI-BLANK; M. D. F., LIMA; R. N., E ALVES, P. Influence of storage time and temperature on the chemical composition of the essential oil of Hyptis pectinata L. Poit. Revista Brasileira de Plantas Medicinais, v. 18, n. 1, p. 336-340, 2016. Disponível em: http://dx.doi.org/10.1590/1983-084X/15_177.

KURIAKOSE, G.C; ARATHI, B.P; LAKSHMANAN, M.D; JIBY, M.V; GUDDE, R.S; JAYABHASKARAN, C. Avaliação da toxicidade subaguda de taxol isolado de 
Fusarium Solani, um fungo endofítico de Taxus Brevifolia, em ratos Wistar e análise de sua citotoxicidade e potencial apoptótico em células de câncer de pulmão. Frontiers in Oncology, v. 10, 2020. Disponível em: https://doi.org/10.3389/fonc.2020.538865.

LAI, S. Cancer related fatigue and cancer cachexia are the consequence of endocrine failure caused by persistent stress. Medical Hypotheses, v. 123, p. 60-62, 2019. Disponível em: https://doi.org/10.1016/j.mehy.2018.12.018.

LANDIS-PIWOWAR, K. R.; IYER, N. R. Cancer chemoprevention: current state of the art. Cancer growth and metastasis, v. 7, p. 19, 2014. Disponível em: https://www.ncbi.nlm.nih.gov/pmc/articles/PMC4064948/DOI: 10.4137/CGM.S11288.

LE, Q. V.; YANG, G.; WU, Y.; JANG, H. W.; SHOKOUHIMEHR, M.; OH, Y. K. Nanomaterials for modulating innate immune cells in cancer immunotherapy. Asian Journal of pharmaceutical Sciences. v. 14, Issue 1, p. 16-29, 2019. Disponível em: https://doi.org/10.1016/j.ajps.2018.07.003.

LI, Y.; ATKINSON, K.; ZHANG, T. Combination of chemotherapy and cancer stem cell targeting agents: Preclinical and clinical studies. Cancer Letters, v. 396, p. 103109 2017. Disponível em: https://doi.org/10.1016/j.canlet.2017.03.008.

LI, W.; DENG, Y.; CHU, Q.; ZHANG, P. Gut microbiome and cancer immunotherapy. Cancer Letters. v. 447, p. 41-47, $2019 . \quad$ Disponível em: https://doi.org/10.1016/j.canlet.2019.01.015.

LIU, W.; LI, J.C; HUANG, J.; CHEN, J.; HOLZBEIERLEIN, J.; LI, B. Alternol / Alteronol: potentes compostos anticancerígenos com múltiplas ações mecanísticas. Frontiers in Oncology, v. 10, 2020. Disponível em: https://doi.org/10.3389/fonc.2020.568110

MACHADO R. B.; PEREIRA E.; CALDAS D.; GONÇALVES N.; SANTOS K.; TABOR E.; STEININGER, M. Estimativas de perda da área do Cerrado brasileiro. Conservation International, Brasília - DF. 2004. Disponível em: http://hmjbb.ibict.br/bitstream/1/357/1/2004_\%20Conservacao\%20Internacional_\%20estimativ a_desmatamento_cerrado.pdf.

MARZO-CASTILLEJO, M.; BELLAS-BECEIRO, B., VELA-VALLESPÍN; C., NUINVILLANUEVA; M., BARTOLOMÉ-MORENO, C.; MELÚS-PALAZÓN, E. E; VILARRUBÍ-ESTRELLA, M. Recomendaciones de prevención del cáncer. Actualización 2016. Atención primaria, v. 48, p. 39-59, 2016. Disponível em: https://zaguan.unizar.es/record/56172/files/texto_completo.pdf/DOI: 10.1016/S02126567(18)30362-7.

MEYERS K. J.; WATKINS C. B.; PRITTS M. P.; LIU R. H. Antioxidant and Antiproliferative Activities of Strawberries. J. Agric. Food Chem. 2003; 51: 68876892. Disponível em: https://doi.org/10.1021/jf034506n.

MILLER, K. D.; MILLER, K. D.; SIEGEL, R. L.; LIN, C. C.; MARIOTTO, A. B.; KRAMER, J. L.; ROWLAND, J. H.; ... \& JEMAL, A. Cancer treatment and 
survivorship statistics, 2016. CA: a cancer journal for clinicians, v. 66, n. 4, p. 271 289, 2016. Disponível em: https://doi.org/10.3322/caac.21349.

MUKHERJEE, S. O Imperador de todos os males: Uma biografia do câncer. São Paulo: Companhia das Letras; 2012. 634 p. ISBN: 978-85-359-2006-2.

NEWMAN D. J.; CRAGG G. M.; SNADER K. M. Natural products as sources of new drugs over the period 1981-2002. Natural Products Reporter. 2003; 66: 1022-1037. Disponível em: https://doi.org/10.1021/np030096I.

NINMANAPALLI R.; PERKINS C. L.; ORLANDO M. Pretreatment with paclitaxel enhances apo-2 ligand/tumor necrosis fator-related apoptosis-inducing ligandinduced apoptosis of prostate câncer cells by inducing death receptors 4 and 5 protein levels. Cancer Research. 2001; 61(2): 759-63. Disponível em: https://cancerres.aacrjournals.org/content/61/2/759.full-text.pdf.

NORBERT, K. Podophyllum peltatum-podofillotoxin. Gyógyszerészet, v. 60, n. 11, p. 661-663, 2016. Disponível em: http://publicatio.bibl.uszeged.hu/10248/1/kusz_norbert_u.pdf. Acesso em 15 julho 2020.

NOBILI S.; LIPPI D.; WITORT E.; DONNINI M.; BAUSI L.; MINI E.; CAPACCIOLI E. Natural compounds for cancer treatment and prevention. Pharmacological Research. 2009; 59: 365-378. Disponível em: https://doi.org/10.1016/j.phrs.2009.01.017.

OWEN, C.; OWEN, C.; PATRON, N. J.; HUANG, A.; OSBOURN, A. Harnessing plant metabolic diversity. Current opinion in chemical biology, v. 40, p. 24-30, 2017. Disponível em: https://doi.org/10.1016/j.cbpa.2017.04.015.

QU, Y.; SAFONOVA, O.; DE LUCA, V. Conclusão da via canônica para montagem de medicamentos anticâncer vincristina / vinblastina em Catharanthus roseus. The Plant Journal, v. 97, n. 2, p. 257-266, 2019. Disponível em: https://doi.org/10.1111/tpj.14111.

RAK J.; FINKENZELLER G.; GRUGEL S.; MARMÉ D.; KERBEL R.S. Oncogenes as inducers of tumor angiogenesis. Cancer Metastasis Reviews. 1995; 14: 263-277. Disponível em: https://www.ncbi.nlm.nih.gov/pubmed/8821090

ROKHFOROZ, P.; JAMSHIDI, A. A.; SARVESTANI, N. N. Adaptive robust control of cancer chemotherapy with extended Kalman filter observer. Informatics in Medicine Unlocked, v. 8, p. 1-7, 2017. Disponível em: https://doi.org/10.1016/j.imu.2017.

SACOMAN J. L.; MONTEIRO K. M.; POSSENTIA, F. G. M.; FOGLIO M. A.; CARVALHO J. E. Cytotoxicity and antitumoral active of dichloromethane extraxt and its ractions from Pothomorphe umbellate. Brazilian Journal of Medical and Biological Research. 2007; 41: 411-415.

SAITO, R. F.; LANA, M. V. G.; MEDRANO, R. F. V.; CHAMMAS, R. Fundamentos de oncologia molecular. São Paulo: Atheneu, 501p. 2015. Disponível em: http://observatorio.fm.usp.br/handle/OPI/24556. 
SANTOS-LIMA, T. M.; SANTOS, D. R.; SOUZA, R. M.; BASTOS, N. G.; SANTOS, M. A. V. D.; NUNES, E. S. e LIMA, A. G. D Plantas medicinais com ação antiparasitária: conhecimento tradicional na etnia Kantaruré, aldeia Baixa das Pedras, Bahia, Brasil. Revista Brasileira de Plantas Medicinais, Campinas, v.18, n.1, supl. I, p.240-247, 2016. Disponível em: http://dx.doi.org/10.1590/1983084X/15_063.

SCHNEIDER, B. J.; KALEMKERIAN, G. P.; GADGEEL, S. M.; VALDIVIESO, M.; HACKSTOCK, D. M.; CHEN, W.; ... E WOZNIAK, A. J. Estudo de fase II de pemetrexedo, gemcitabina e bevacizumabe denso em dose em pacientes com câncer de pulmão avançado de células não pequenas. Câncer de pulmão clínico, v. 18, n. 3, p. 299-302, 2017. Disponível em: https://doi.org/10.1016/j.cllc.2016.11.019.

SIDDIQUI, I. A.; SANNA, V.; AHMAD, N.; SECHI, M.; MUKHTAR, H. Resveratrol nano formulation for cancer prevention and therapy. Annals of the New York Academy of Sciences, v. 1348, n. 1, p. 20-31, 2015. Disponível em: http://dx.doi.org/10.1111/nyas.12811.

SIMÕES, C. M. O., SCHENKEL, E. P., DE MELlO, J. C. P., MENTZ, L. A., \& PETROVICK, P. R. Farmacognosia: do produto natural ao medicamento. Artmed Editora. 2016.2 Disponível em: https://books.google.com.br/books?id=uo5vDQAAQBAJ\&lpg=PT12\&ots=1CdKsmwmi\&dq=Farmacognosia\%3A\%20da\%20planta\%20ao\%20medicamento\&lr\&hl=pt-.

SUN, H.; LI, C.; NI, Y.; YAO, L.; JIANG, H.; REN, X.; ... e ZHAO, C. Extração ultrassônica / assistida por microondas de polissacarídeos de frutos de Camptotheca acuminata e sua atividade antitumoral. Polímeros de carboidratos, 206, 557-564. 2019. Disponível em: https://doi.org/10.1016/j.carbpol.2018.11.010.

TAIZ L.; ZEIGER E. Fisiologia vegetal. Porto Alegre: Artmed, p.449-484. 2004.

TANAKA, T. Role of apoptosis in the chemo prevention of cancer. Journal of Experimental \& Clinical Medicine, v. 5, n. 3, p. 89-91, 2013. Disponível em: https://doi.org/10.1016/j.jecm.2013.04.001

TANAKA, T.; SHIMIZU, M.; KOCHI, T.; MORIWAKI, H. Chemical-induced carcinogenesis. Journal of Experimental \& Clinical Medicine, v. 5, n. 6, p. 203209, 2013. Disponível em: http://dx.doi.org/10.1016/j.jecm.2013.10.009.

THURSTON, D. E. Chemistry and Pharmacology of Anticancer Drugs. (Taylor \& Francis), Boca Raton FL, USA: CRC Press; 2006. 281p. Disponível em: https://books.google.com.br/books?id=6mPLBQAAQBAJ\&lpg=PP1\&ots=LVC_pkLkr. Acesso em 10 julho 2020.

TUGBOBO, O. S.; ALUKO, B. T.; IDOWU, K. S.; FAYOSE, T. S.; BABATOLA, L. J. Hipertensão individual por sedimentos radioativos e risco de câncer; modificação possível por extrato de folha de Podophyllum peltatum. Journal of Global Biosciences, v. 9, n. 1, p. 6708-6717, 2020. 
VIEIRA, V. S; CRUZ, V. D. S. P., PEIXOTO, N.P. FAQUIN, S. R. C. P. F., \& ARAÚJO, E. G. Câncer de pulmão de não pequenas células. Enciclopédia Biosfera, Centro Científico Conhecer - Goiânia, v.14 n.25; p. 2017. Disponível em: http://www.conhecer.org.br/enciclop/2017a/sau/cancer.pdf.

10.18677/EnciBio_2017A126.

ZHANG, K.; DAI, H.; LIANG, W.; ZHANG, L.; DENG, Z. Fermented dairy foods intake and risk of cancer. International journal of cancer, v. 144, n. 9, p. 2099-2108, 2019. Disponível em: https://doi.org/10.1002/ijc.31959.

ZHAO, D., HAMILTON, JP, PHAM, GM, CRISOVAN, E., WIEGERT-RININGER, K., VAILLANCOURT, B., ... e BUELL, C. R. Montagem do novo genoma de Camptotheca acuminata, uma fonte natural do composto anticâncer camptotecina. GigaScience, 6 (9), 2017. Disponível em: https://doi.org/10.1093/gigascience/gix065.

ZILLA, MAHESH K.; NAYAK, D., VISHWAKARMA, R. A., SHARMA, P. R., GOSWAMI, A., \& ALI, A. A convergent synthesis of alkyne-azide cycloaddition derivatives of $4-\alpha, \beta-2$-propyne podophyllotoxin depicting potent cytotoxic activity. European journal of medicinal chemistry, v. 77, p. 47-55, 2014 B. Disponível em: https://doi.org/10.1016/j.ejmech.2014.02.030.

WEINSTEIN, I. B.; JOE, A. K. Mechanisms of disease: Oncogene addiction--a rationale for molecular targeting in cancer therapy. Nature Reviews. Clinical Oncology, v. 3, n. $8, \quad$ p. 448, 2006 . Disponível em: https://www.nature.com/articles/ncponc0558/DOI:10.1038/ncponc0558. 